\title{
Interval versus continuous training in patients with severe COPD: a randomized clinical trial
}

\author{
R. Coppoolse*, A.M.W.J. Schols*, E.M. Baarends*, R. Mostert**, \\ M.A. Akkermans**, P.P. Janssen**, E.F.M. Wouters*
}

Interval versus continuous training in patients with severe COPD: a randomized clinical trial. R. Coppoolse, A.M.W.J. Schols, E.M. Baarends, R. Mostert, M.A. Akkermans, P.P. Janssen, E.F.M. Wouters. (C) ERS Journals Ltd 1999.

ABSTRACT: Limited information is available regarding the physiological responses to different types of exercise training in patients with severe chronic obstructive pulmonary disease (COPD). The aim of this study was two fold: firstly, to investigate the physiological response to training at $60 \%$ of achieved peak load in patients with severe COPD; and secondly to study the effects of interval (I) versus continuous (C) training in these patients.

Twenty-one patients with COPD (mean \pm SD forced expiratory volume in one second: $37 \pm 15 \%$ of predicted, normoxaemic at rest) were evaluated at baseline and after 8 weeks' training. Patients were randomly allocated to either $\mathrm{I}$ or $\mathrm{C}$ training. The training was performed on a cycle ergometer, 5 days a week, 30 min daily. The total work load was the same for both training programmes.

$C$ training resulted in a significant increase in oxygen consumption $\left(V^{\prime} \mathrm{O}_{2}\right)(17 \%$, $\mathrm{p}<0.05)$ and a decrease in minute ventilation $\left(V^{\prime} E\right) / V^{\prime} \mathrm{O}_{2}(\mathrm{p}<0.01)$ and $V^{\prime} E /$ carbon dioxide production $\left(V^{\prime} \mathrm{CO}_{2}\right)(\mathrm{p}<0.05)$ at peak exercise capacity, while no changes in these measures were observed after interval training. During submaximal exercise a significant decrease was observed in lactic acid production, being most pronounced in the $\mathrm{C}$-trained group $(-31 \%, p<0.01$ versus $-20 \%, p<0.05)$. Only in the I-trained group did a significant increase in peak work load $(17 \%, p<0.05)$ and a decrease in leg pain $(p<0.05)$ occur. Training did not result in a significant improvement in lung function, but maximal inspiratory mouth pressure increased in both groups by $10 \%(C: p<0.05)$ and $23 \%$ (I: $p<0.01$ ).

The present study shows a different physiological response pattern to interval or continuous training in chronic obstruction pulmonary disease, which might be a reflection of specific training effects in either oxidative or glycolytic muscle metabolic pathways. Further work is required to determine the role of the different exercise programmes and the particular category of patients for whom this might be beneficial. Eur Respir J 1999; 14: 258-263.
**Astmacentre Hornerheide, and *Dept of Pulmonology, Maastricht University, the Netherlands.

Correspondence: A.M.W.J. Schols

Dept of Pulmonology

P.O. Box 5800

6202 AZ Maastricht

The Netherlands

Fax: 31433875051

Keywords: Chronic obstructive pulmonary disease

continuous work training

exercise

interval training

muscle

rehabilitation

Received: September 241997

Accepted after revision April 61999
Pulmonary rehabilitation has become a cornerstone in an integrated management of patients with chronic obstructive pulmonary disease (COPD) [1]. Dyspnoea and an impaired exercise tolerance are prominent complaints in these patients and exercise training is therefore an essential component of a pulmonary rehabilitation programme [1]. Although several studies have shown beneficial effects of exercise training on exercise tolerance in COPD, the question persists as to whether these increases are principally due to improved psychological benefits of pulmonary rehabilitation or to improved physiological ability to perform exercise.

The physiological response to exercise depends on four training principles [2]. 1) A specific exercise overload must be applied to enhance physiological improvement effectively and to bring about a training change. The appropriate overload can be achieved by manipulating combinations of training frequency, intensity, mode and duration. It was long believed that in COPD patients this overload principle could not be applied due to dyspnoea at low work rates. However, CASABURI et al. [3] clearly showed, in patients with moderate COPD a higher physiological training response after high intensity training compared to low intensity training. 2) The second training principle refers to the dependence of the metabolic and physiological systems on the type of overload. 3) Training benefits are optimized when programmes are planned to meet the individual needs and capacities of the participants. Besides the compromized lung function, a number of reports during the last 5 yrs have drawn attention to other relevant patients characteristics in COPD such as body composition [4], peripheral muscle strength [5] and muscle metabolic status [6]. This implies that in order to meet individual needs in training of patients with COPD, these patients should be extensively characterized. 4) Lastly, exercise training is transient and reversible.

In order to evaluate exercise training in COPD, randomized clinical trials in well defined patients should be performed with appropriate effect measures. Remarkably, only very limited controlled studies are yet available in the 
literature investigating exercise training in patients with severe COPD. The aim of this study was therefore twofold: firstly, to investigate the physiological response to training in patients with severe COPD and, secondly, to study the effects of interval versus continuous training in these patients. The interest in assessing interval training was based upon previous experience of the acceptance of this training type in clinical practice and because interval exercise resembles the daily life activity pattern in severe COPD patients more than continuous exercise [7].

\section{Methods}

\section{Patients and inclusion criteria}

Patients with moderate-to-severe COPD (as defined by the American Thoracic Society) were studied (table 1). In order to create a homogeneous population, only male patients entered the study. They were consecutively admitted to the inpatient pulmonary rehabilitation programme in a stable clinical condition after referral by their pulmonary physician. Patients exhibiting an increase in forced expiratory volume in one second (FEV1) $>10 \%$ of predicted baseline after inhalation of a $\beta_{2}$-agonist were excluded. The patients had no known coronary, orthopaedic, neurological or endocrine disorders. In view of the increased risks of high-intensity exercise training in patients with severe hypoxaemia, patients with a resting arterial oxygen tension $\left(\mathrm{Pa}_{\mathrm{a}} \mathrm{O}_{2}\right)<9.0 \mathrm{kPa}$ were excluded. Since in a similar rehabilitation population a significant relationship between nutritional depletion and impaired exercise tolerance has previously been determined [4] and since depleted patients (i.e. fat-free mass index $<16 \mathrm{~kg} \cdot \mathrm{m}^{-2}$ or $67 \%$ of ideal weight) all received standardized nutri-

Table 1. - Baseline characteristics stratified by the two training groups

\begin{tabular}{|c|c|c|}
\hline Training & Continuous & Interval \\
\hline Age yrs & $67 \pm 3$ & $63 \pm 8$ \\
\hline Height $\mathrm{cm}$ & $172 \pm 8$ & $173 \pm 7$ \\
\hline Weight $\mathrm{kg}$ & $73 \pm 9$ & $75 \pm 15$ \\
\hline BMI $\mathrm{kg} \cdot \mathrm{m}^{-2}$ & $24.7 \pm 9$ & $25.1 \pm 10$ \\
\hline FFM kg & $52 \pm 6$ & $55 \pm 8$ \\
\hline FFMI $\mathrm{kg} \cdot \mathrm{m}^{-2}$ & $17.4 \pm 1.8$ & $18.7 \pm 2.9$ \\
\hline$P_{\mathrm{a}, \mathrm{O}_{2}} \mathrm{kPa}$ & $10.0 \pm 0.9$ & $10.8 \pm 1.2$ \\
\hline 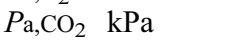 & $4.54 \pm 1.7$ & $5.07 \pm 1.9$ \\
\hline $\mathrm{pH}$ & $7.42 \pm 0.02$ & $7.39 \pm 0.05$ \\
\hline FEV1 \% pred & $37.4 \pm 18.2$ & $36.2 \pm 10.3$ \\
\hline FVC \% pred & $93.4 \pm 17.4$ & $81.6 \pm 12.2$ \\
\hline TLC $\%$ pred & $125.5 \pm 19.7$ & $124.6 \pm 20.6$ \\
\hline RV \% pred & $192.8 \pm 65.9$ & $208.1 \pm 66.0$ \\
\hline MIP $\mathrm{cmH}_{2} \mathrm{O}$ & $73.8 \pm 13.6$ & $71.5 \pm 19.7$ \\
\hline$D \mathrm{~L}, \mathrm{CO} \%$ & $46.4 \pm 12.1$ & $59.4 \pm 19.4^{*}$ \\
\hline Wmax $W$ & $67 \pm 18$ & $75 \pm 17$ \\
\hline$V^{\prime} \mathrm{O}_{2}, \max \mathrm{L} \cdot \min ^{-1}$ & $0.91 \pm 0.24$ & $1.14 \pm 0.18 *$ \\
\hline
\end{tabular}

Data are presented as mean \pm SD. BMI: body mass index; FFM: fat-free mass; FFMI: fat-free mass index; $P_{\mathrm{a}, \mathrm{O}_{2}}$ : arterial oxygen tension; $P \mathrm{a}, \mathrm{CO}_{2}$ : arterial carbon dioxide tension; FEV1: forced expiratory volume in one second; FVC forced vital capacity; TLC: total lung capacity; RV: residual volume; MIP: maximal static inspiratory pressure; $D$ L,CO: lung diffusion capacity for carbon monoxide; Wmax: peak work load; $V^{\prime} \mathrm{O}_{2}$, max: maximum oxygen consumption. ${ }^{*}: \mathrm{p}<0.05$. tional support, the latter were excluded from the study. Furthermore patients were excluded if they failed to reach at least $50 \mathrm{~W}$ during the first incremental exercise test, to be able to set up high-intensity training and define a reliable lactic acid threshold (LAT).

\section{Measurements}

Before and one day after the training period, patients were tested. In addition, to avoid possible learning effects, an extra lung function and exercise test was performed the week before the training period. The second tests were used in the analysis of the results.

\section{Lung function and body composition}

FEV1 and forced vital capacity (FVC) were measured; the highest value of at least three manoeuvres was used. Residual volume (RV) and total lung capacity (TLC) were measured by body plethysmography (Masterlab; Jaeger, Würzburg, Germany) and lung diffusion capacity for carbon monoxide ( $D$ L,CO) was measured at rest by a single breath method. Inspiratory muscle strength was assessed by maximal static inspiratory pressure (MIP) according to the technique described by Black and HyatT [8]. The highest value of at least three measurements was chosen. Arterial blood was drawn by puncture of the radial artery at rest while breathing room air and was analysed for $P \mathrm{a}, \mathrm{O}_{2}$, arterial carbon dioxide tension $\left(\mathrm{Pa}_{\mathrm{a}} \mathrm{CO}_{2}\right)$, arterial oxygen saturation $\left(\mathrm{Sa}_{\mathrm{a}} \mathrm{O}_{2}\right)$ and $\mathrm{pH}$ (ABL 330; Radiometer, Copenhagen, Denmark). Body composition was assessed by bioelectrical impedance analysis [9].

\section{Exercise tests}

To assess the physiological training response to exercise, an incremental exercise test and a constant work rate (CWR) test were performed on an electromagnetically braked cycle ergometer (Examiner; Lode, Groningen, the Netherlands) on two succeeding days. The protocol of the incremental cycle test was as follows: after 2 min rest, followed by $1 \mathrm{~min}$ unloaded pedalling, the work rate was increased by $10 \mathrm{~W}$ every minute until exhaustion occurred. Metabolic and ventilatory measures were assessed breath by breath using a commercial automated system (Oxyconbeta; Jaeger). Cardiac frequency was measured using a sporttester (PE 3000; Polar electro cy, Kempele, Finland). The visual analogue scale (VAS) was administered to the patients to assess fatigue in the legs and dyspnoea at peak work rate. Venous blood samples were taken at rest and every minute during the test from the forearm. The blood samples were stored in ice until analysed and plasma lactate was measured within $2 \mathrm{~h}$ by an automated enzymatic method (Cobas Mira; Roche, Mannheim, Germany). The LAT was defined as the oxygen consumption $\left(V^{\prime} \mathrm{O}_{2}\right)$ corresponding to the point at which an accelerated increase in lactate concentration occurs [10]. In order to prevent random misinterpretations, the LAT was selected by a mathematical technique and calculated as the intersection point of two straight line segments in a log-to-log plot. 
The CWR test was performed at a work rate corresponding to $90 \%$ of the LAT. When the LAT could not be detected, a workload of $45 \%$ of peak work load (Wmax) was used. This value was chosen after a retrospective analysis had been performed from the database of the pulmonary rehabilitation centre, showing that $90 \%$ of the LAT corresponded to $45 \%$ of the peak work rate. The test lasted $13 \mathrm{~min}$, which was chosen to be able to determine whether the exercise intensity was indeed below or above the anaerobic threshold [10] and to be able to assess whether the patients had reached a steady state. The $V^{\prime} \mathrm{O}_{2}$, carbon dioxide production $\left(V^{\prime} \mathrm{CO}_{2}\right)$, ventilation and cardiac frequency were measured as described for the incremental exercise test. Furthermore, as described for the incremental cycle test, venous blood samples were obtained during the CWR to measure lactate. Blood samples were taken at rest, every 2 min during exercise and at 2 min after completing the test.

\section{Study design}

Patients were assigned to either the interval training group or the continuous training group by block randomization following a list of random numbers [11]. The patients trained on a cycle ergometer (Lode) $30 \mathrm{~min} \cdot \mathrm{day}^{-1}$, 5 day.week ${ }^{-1}$, for 8 weeks. The intensity of training was defined as a percentage of the peak work rate in the pretraining incremental exercise test. The patients in the continuous training group trained 5 day. $\mathrm{week}^{-1}$ at $60 \%$ of the peak work rate. The patients who were assigned to the interval training group received interval training 3 day. week ${ }^{-1}$ which consisted of nine blocks including 3 min of alternated $90 \%(1 \mathrm{~min})$ and $45 \%(2 \mathrm{~min})$ of the peak work rate as shown in figure 1 . The other 2 days consisted of continuous training at $60 \%$ of the peak work rate. Total work was kept constant for the two training groups. It was recognized that since the interval training group also received 2 days of continuous training each week, the contrast between the two training groups would be smaller. However, this design is commonly used in sports i.e. to prevent overload injuries as a result of the peak stress on the musculoskeletal system.

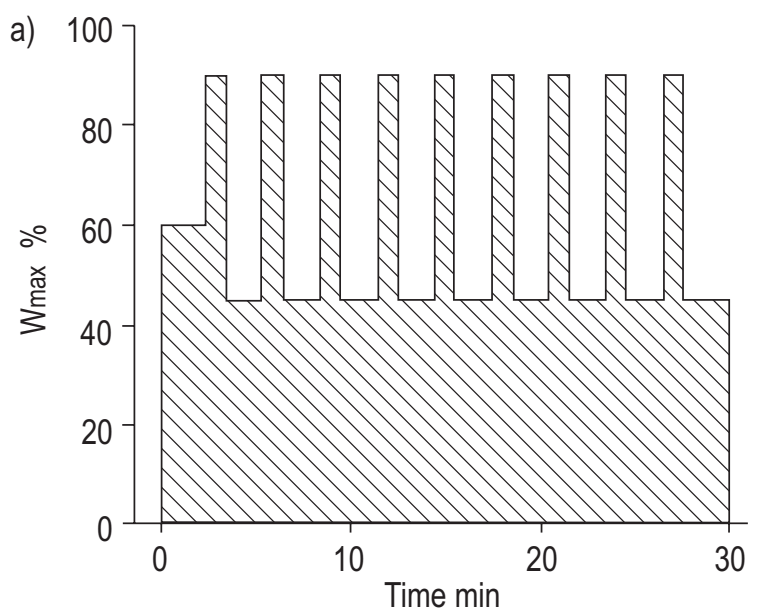

\section{Other pulmonary rehabilitation components}

Other components of the rehabilitation programme i.e. physical therapy, gymnastics, relaxation and education were standardized. Patients who entered the study were not engaged in a previous exercise programme. During the study no other exercise training programmes such as strength training and respiratory muscle training were given. Medical therapy was standardized and remained unchanged during the training period.

\section{Statistical analysis}

The results are expressed in mean \pm SD unless otherwise stated. Differences within exercise groups were tested by the Wilcoxon log-rank test and differences between the groups by Student's t-test, where appropriate, or the Mann-Whitney U-test. A p-value $<0.05$ was considered to be statistically significant. Statistical analyses were performed using the SPSS-Windows package (SPSS Inc, Chicago, IL, USA). The Bonferroni adjustment was performed were appropriate.

\section{Results}

Baseline patient characteristics for each training group are shown in table 1. Twenty-one patients entered the study. The group was characterized by severe airflow obstruction, a reduced DL,CO and elevated RV and TLC. The MIP was markedly decreased. Resting arterial blood gas levels were within the normal range. Randomization assigned 11 patients to the continuous training group and 10 to the interval training group. One patient in each group dropped out of the study due to factors unrelated to the training programme. Resting lung function characteristics after randomization did not show statistically significant differences between the study groups (table 1). However, the interval training group demonstrated a higher peak oxygen uptake $(24 \%)$ and DL,CO $(28 \%)$. Baseline DL,CO was significantly related to baseline peak oxygen uptake $(\mathrm{r}=0.56 ; \mathrm{p}=0.012)$, but not to changes in $V^{\prime} \mathrm{O}_{2}(\mathrm{r}=0.16$; NS).

Since limited data are available regarding physiological training effects in severe COPD patients, the total study group was analysed prior to investigation of possible

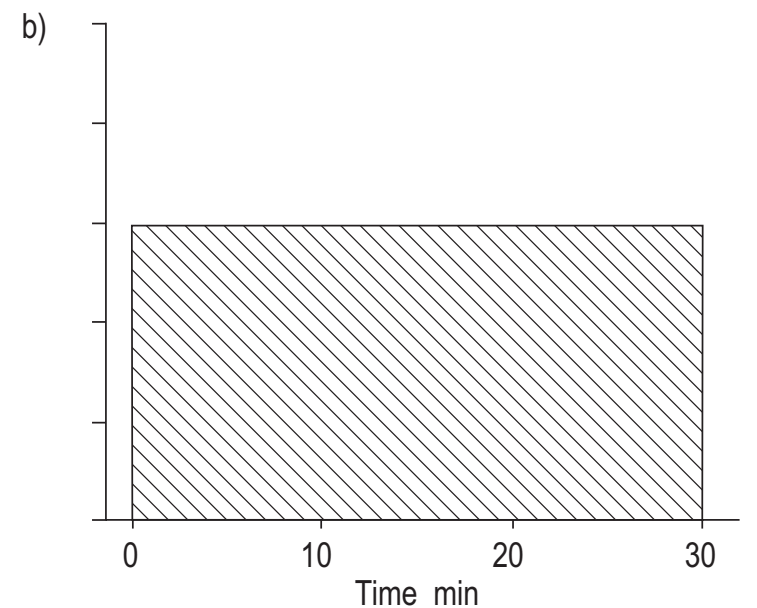

Fig. 1. - Protocol of: a) interval; and b) continuous training. $W_{\max }$ : peak work load. 
Table 2. - Comparison of the exercise test measurements before and after training for the total study group

\begin{tabular}{|c|c|c|c|}
\hline & $\begin{array}{l}\text { Pre- } \\
\text { training }\end{array}$ & $\begin{array}{l}\text { Post- } \\
\text { training }\end{array}$ & $\begin{array}{c}\text { Change } \\
\%\end{array}$ \\
\hline \multicolumn{4}{|l|}{ Incremental exercise test } \\
\hline$W_{\max } \mathrm{W}$ & $71 \pm 18$ & $81 \pm 23$ & $14 * * *$ \\
\hline$V^{\prime} \mathrm{O}_{2}, \max \mathrm{L} \cdot \mathrm{min}^{-1}$ & $1.0 \pm 0.2$ & $1.1 \pm 0.3$ & $12 * *$ \\
\hline$V^{\prime} \mathrm{E}, \max \mathrm{L} \cdot \mathrm{min}^{-1}$ & $42.4 \pm 10.4$ & $43.7 \pm 10.7$ & 8 \\
\hline$V^{\prime} \mathrm{E} / V^{\prime} \mathrm{O}_{2}$ & $42.2 \pm 8.6$ & $39.2 \pm 7.2$ & $7 * *$ \\
\hline$V^{\prime} \mathrm{E} / V^{\prime} \mathrm{CO}_{2}$ & $43.7 \pm 7.7$ & $40.6 \pm 7.1$ & 7* \\
\hline$V \mathrm{~T} \mathrm{~L} \cdot \min ^{-1}$ & $1.4 \pm 0.2$ & $1.6 \pm 0.8$ & 14 \\
\hline$f \mathrm{R}, \max$ breaths $\cdot \min ^{-1}$ & $30.5 \pm 5.2$ & $30.7 \pm 4.4$ & 1 \\
\hline$f \mathrm{C}, \max$ beats $\cdot \min ^{-1}$ & $134 \pm 13$ & $136 \pm 19$ & 2 \\
\hline Lactate, $\max \mathrm{mmol} \cdot \mathrm{L}^{-1}$ & $4.2 \pm 1.6$ & $4.1 \pm 1.3$ & 2 \\
\hline VAS dyspnoea mm & $71 \pm 25$ & $68 \pm 24$ & 4 \\
\hline VAS leg pain $\mathrm{mm}$ & $36 \pm 29$ & $17 \pm 28$ & $53 * *$ \\
\hline \multicolumn{4}{|l|}{ Constant work rate test } \\
\hline$V^{\prime} \mathrm{O}_{2} \mathrm{~L} \cdot \min ^{-1}$ & $0.8 \pm 0.2$ & $0.8 \pm 0.1$ & 0 \\
\hline$V^{\prime} \mathrm{E} \mathrm{L} \cdot \mathrm{min}^{-1}$ & $34.4 \pm 7.2$ & $34.0 \pm 5.6$ & 1 \\
\hline$V \mathrm{~T} \mathrm{~L} \cdot \mathrm{min}^{-1}$ & $1.27 \pm 0.21$ & $1.33 \pm 0.24$ & 8 \\
\hline$f \mathrm{R}$ breaths $\cdot \min ^{-1}$ & $27.2 \pm 4.1$ & $25.9 \pm 3.7$ & $5^{*}$ \\
\hline$f \mathrm{C}$ beats $\cdot \mathrm{min}^{-1}$ & $118 \pm 16$ & $117 \pm 13$ & 1 \\
\hline Lactate $\mathrm{mmol} \cdot \mathrm{L}^{-1}$ & $3.9 \pm 1.5$ & $2.9 \pm 1.2$ & $26^{* * *}$ \\
\hline
\end{tabular}

Data are presented as mean \pm SD. $W_{\max }$ : peak work load; $V^{\prime} \mathrm{O}_{2}$, max maximum oxygen consumption; $V^{\prime} \mathrm{E}$,max: maximal minute ventilation; $V^{\prime} \mathrm{CO}_{2}$ : carbon dioxide production; $V \mathrm{~T}$ : tidal volume; $f \mathrm{R}$,max: respiratory frequency; $f \mathrm{C}$,max: maximum cardiac frequency; Lactate,max: maximum lactate concentration; VAS: visual analogue scale. ${ }^{*}: \mathrm{p}<0.05 ;{ }^{* *}: \mathrm{p}<0.01 ; * * *: \mathrm{p}<0.001$.

differences between the exercise groups (table 2). Table 2 shows the relevant peak exercise response measures before and after training. Peak work load (mean difference $10 \mathrm{~W}, 95 \%$ confidence interval (CI) 4-16 W) and peak $V^{\prime} \mathrm{O}_{2}$ (mean difference $0.1 \mathrm{~L} \cdot \mathrm{min}^{-1}, 95 \%$ CI $0.04-0.18$ $\mathrm{L} \cdot \mathrm{min}^{-1}$ ) were significantly increased, but no significant changes were seen in peak minute ventilation $\left(V^{\prime} \mathrm{E}\right)$, respiratory frequency $(f \mathrm{R})$, tidal volume $(V \mathrm{~T})$ and cardiac frequency. In turn, $V^{\prime} \mathrm{E} / V^{\prime} \mathrm{O}_{2}$ was significantly decreased. Furthermore, the VAS measuring leg fatigue at peak work rate was significantly decreased (mean difference 19.4 $\mathrm{mm}, 95 \%$ CI $5.3-33.4 \mathrm{~mm}$ ), while no difference was observed in the VAS measuring dyspnoea.
Table 2 also shows the effects of training on the CWR test. Lactic acid production during steady state of the CWR test was significantly decreased after training (mean difference $1.0 \mathrm{mmol} \cdot \mathrm{L}^{-1}$, CI $0.6-1.4 \mathrm{mmol} \cdot \mathrm{L}^{-1}$ ). No significant changes were seen in oxygen uptake. Although $V^{\prime} \mathrm{E}$ was not significantly different (mean difference $0.5 \mathrm{~L} \cdot \mathrm{min}^{-1}, 95 \%$ CI $\left.-2.6-1.7 \mathrm{~L} \cdot \mathrm{min}^{-1}\right), f \mathrm{R}$ was significantly reduced after training (mean difference 1.5 breaths $\mathrm{min}^{-1}, 95 \% \mathrm{CI}-3--0.1$ breaths $\cdot \mathrm{min}^{-1}$ ). No correlation was found between the changes in $V^{\prime} \mathrm{E}$ and lactic acid before and after training during the CWR test $(\mathrm{r}=$ 0.21 ; NS). No changes were seen in spirometry and static lung volumes (table 2), but the MIP was significantly increased after training (mean difference $1.1 \mathrm{kPa}, 95 \% \mathrm{CI}$ $0.6-1.7 \mathrm{kPa}$ ).

Figure 2 shows the changes in metabolic response and figure 3 the changes in Wmax, leg pain and MIP after 8 weeks of continuous or interval training. In the continuous training group, peak oxygen uptake increased by $17 \%(\mathrm{p}<0.05)$. No changes were observed in peak $V^{\prime} \mathrm{E}$ or lactic acid production. $V^{\prime} \mathrm{E} / V^{\prime} \mathrm{O}_{2}$ and $V^{\prime} \mathrm{E} / V^{\prime} \mathrm{CO}_{2}$ were significantly decreased $(\mathrm{p}<0.01)$. Wmax and MIP both increased by $\sim 10 \%$ but this change was statistically significant only for MIP $(\mathrm{p}<0.05)$. With respect to the subjective measures, no changes in the VAS score for leg pain or dyspnoea were observed. During the CWR test a significant decrease in lactic acid production $(31 \% ; \mathrm{p}<$ $0.01)$ was seen, but no significant differences in ventilatory parameters or oxygen uptake were observed.

In the interval training group, $\mathrm{Wmax}$ was significantly increased $(17 \% ; \mathrm{p}<0.05)$ but not peak $V^{\prime} \mathrm{O}_{2}$ and therefore the ratio $V^{\prime} \mathrm{O}_{2} / \mathrm{Wmax}$ showed a small but significant decrease $(\mathrm{p}<0.01)$. Leg pain was significantly decreased after interval training $(\mathrm{p}<0.01)$, despite increased lactic acid production (NS) at peak work rate. MIP increased significantly by $23 \%(\mathrm{p}<0.01)$. No significant changes were seen in ventilatory parameters at Wmax or during the CWR test. Lactic acid production in the interval group during the CWR test showed a significant decrease by $20 \%(\mathrm{p}<0.05)$.

Despite a trend towards a different overall metabolic and subjective response pattern between continuous and interval training, comparison of measures between the two

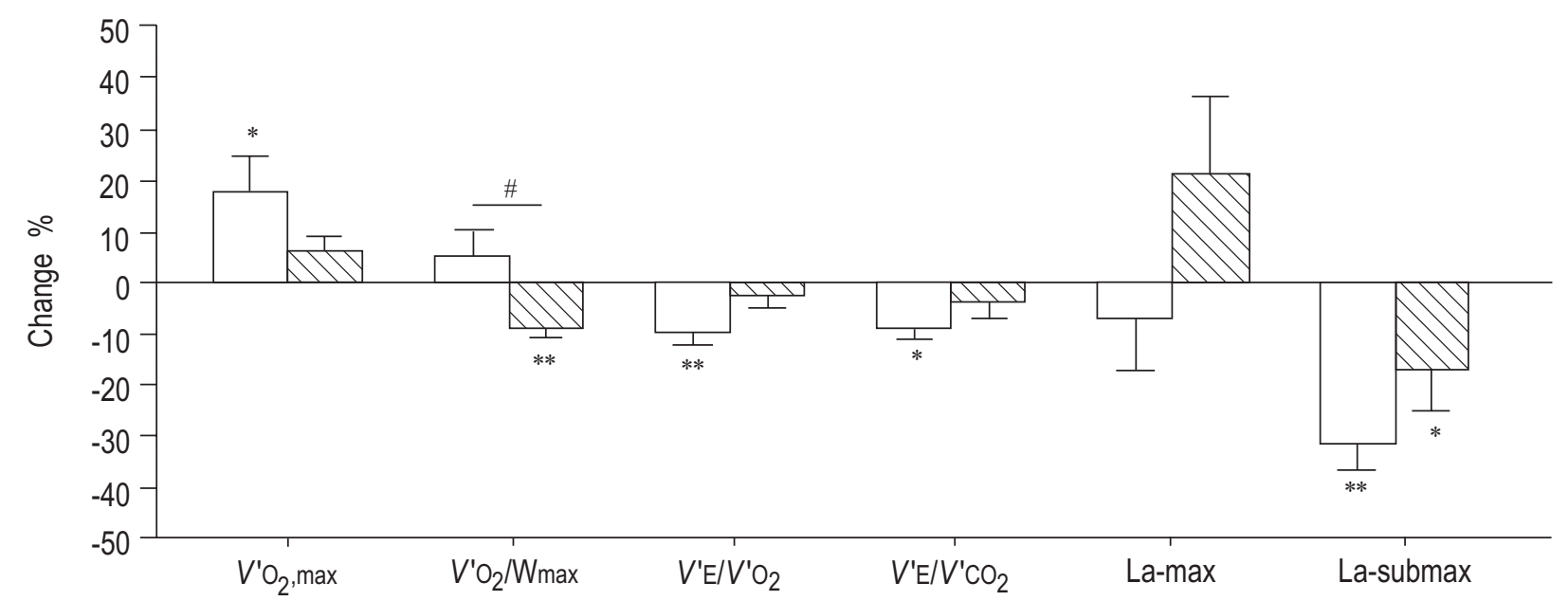

Fig. 2. - Difference in metabolic response pattern after interval $(\mathbb{\nabla})$ and continuous $(\square)$ training. $V^{\prime} \mathrm{O}_{2}$, max: maximum oxygen consumption; $\mathrm{W}_{\max }$ : peak work load; $V^{\prime} \mathrm{E}$ : minute ventilation; $V^{\prime} \mathrm{CO}_{2}$ : carbon dioxide production; La-max: maximum lactate concentration; La-submax: submaximal lactate concentration. *: $\mathrm{p}<0.05$; **: $\mathrm{p}<0.01$, within the group; ${ }^{\#}: \mathrm{p}<0.05$ between interval and continuous training. 


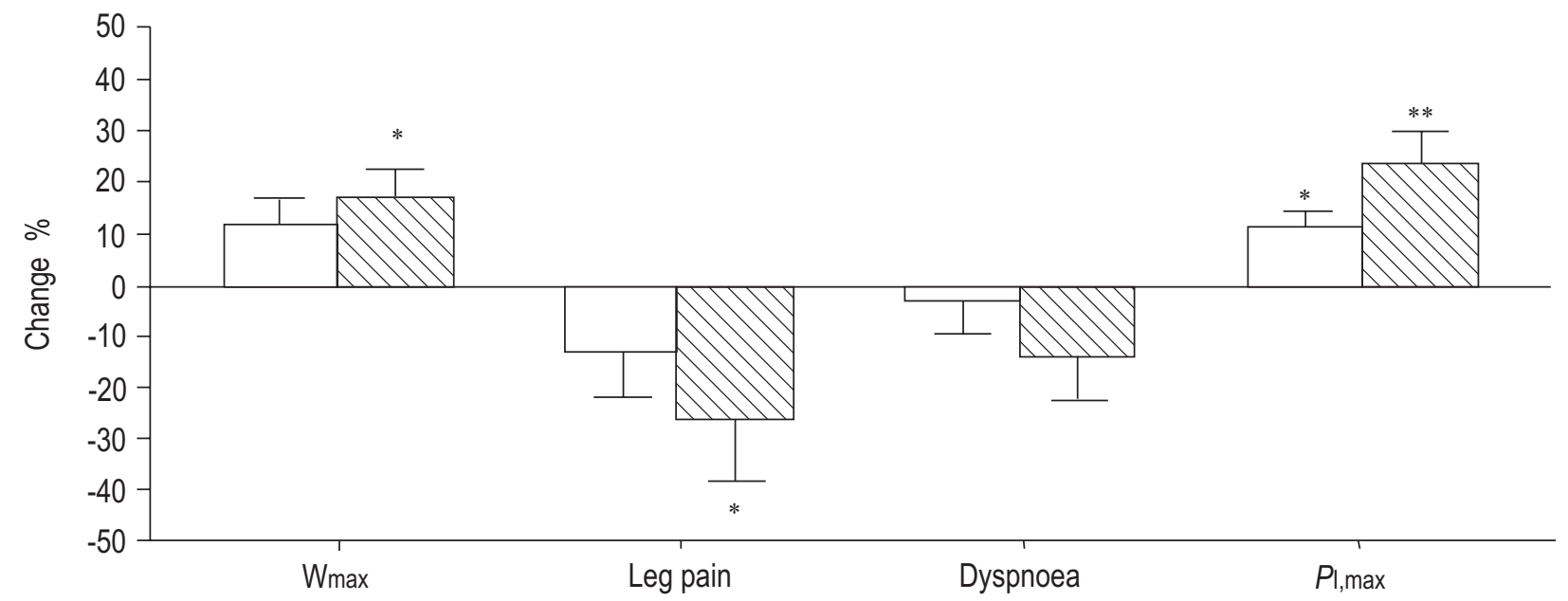

Fig. 3. - Difference in peak work load (Wmax), maximal inspiratory pressure (PI,max), dyspnoea and leg pain after interval ( $\mathbb{\nabla})$ and continuous ( $\square$ ) training. *: $\mathrm{p}<0.05 ; * *: \mathrm{p}<0.01$, within the group.

training groups before and after training, revealed no significant difference in mean changes except for a difference in $V^{\prime} \mathrm{O}_{2} / \mathrm{W} \max (\mathrm{p}<0.05)$.

\section{Discussion}

Lower extremity training addresses the functional impairment in patients with COPD and therefore represents a cornerstone of the interdisciplinary management of patients with COPD in pulmonary rehabilitation [1]. Support for the effectiveness of exercise training in COPD, was recently reported in a review concerning the scientific basis of pulmonary rehabilitation [12]. Examination of the results of the 12 reported randomized controlled trials reveals that most programmes succeeded in improving exercise endurance or $\mathrm{Wmax}_{\max }$, but an increase in peak $V^{\prime} \mathrm{O}_{2}$ consumption was only found in two studies.

In the present study, it was found that an exercise load of $60 \%$ of individual peak work load represented a sufficient stimulus to induce a training response. The need for a sufficient training load was demonstrated by CASABURI et al. [3] who investigated the effect of high- and lowintensity exercise in patients with moderate COPD after 8 weeks training for 5 days a week. The increases in exercise tolerance and the altered lactate response were more pronounced in the high intensity training group, indicating that training intensity is relevant for COPD patients. MaLTAIS et al. [13] recently investigated, in a group of 11 patients with severe COPD, the effects of a moderate intensity continuous training programme on the metabolic and ventilatory response during exercise, arterial lactic acid concentration and enzyme capacity measured in peripheral muscle biopsies. In this study the improvement in exercise capacity was accompanied by a significant increase in oxidative enzyme capacity, whereas no change was observed in glycolytic enzymes.

The training group in the present study was similar to that studied by MALTAIS et al. [13], allowing some comparison between the two studies. In both studies, training resulted in a significant increase in peak work rate, peak $V^{\prime} \mathrm{O}_{2}$ and a significant reduction in lactic acid production. However, in the study by MALTAIs et al. [13], a significant reduction in $V^{\prime} \mathrm{E}$ was seen at high work rates, whereas the present study did not confirm a similar change in $V^{\prime} \mathrm{E}$ during a constant work rate test.

The second aim of the study was to investigate the effects of interval training as an alternative training modality to continuous training. Continuous training stresses the oxidative pathways, while as a result of the short periods of high intensity exercise, interval training also stresses the glycolytic pathways. Interval exercise resembles the daily life activity pattern in severe COPD patients more closely than continuous exercise. One reason for anticipating enhanced exercise tolerance after interval training as compared to continuous work training relates to recent observations in peripheral skeletal muscle biopsies of patients with COPD showing that baseline energy status can be altered, resulting in a shift towards a decreased aerobic enzyme capacity $[6,14]$ and an increased glycolytic capacity [14]. A recent study in 12 healthy subjects trained for 8 weeks, 3 days a week, after being allocated to an interval training group ( $30 \mathrm{~s}$ work, $30 \mathrm{~s}$ rest) or to a continuous training group (50\% maximal work) showed a greater increase in maximum oxygen uptake, exercising work and peak power output after interval training (9$16 \%)$ than after continuous training (5-7\%) [15]. The vastus lateralis citrate activity increased by $25 \%$ after continuous training, whereas no change was seen after interval training [15]. Other studies showed increases in peak $V^{\prime} \mathrm{O}_{2}$ and $\mathrm{Wmax}$ as well but no significant differences were seen between the training modalities [16, 17].

The lack of significant differences in physiological changes between the two training groups in this study is most likely related to the sample size. However, within group changes point towards a difference between the two training modalities in metabolic stress on oxidative and glycolytic pathways. A higher peak $V^{\prime} \mathrm{O}_{2}$ in the continuous training group, accompanied by a more significant decrease in lactic acid production during the submaximal test, are indicative of an increase in oxidative capacity. This may be related to an increase in the number of mitochondria, capillary density and, as was recently shown by MALTAIS et al. [13], the aerobic enzyme capacity. In addition, the lower ventilatory equivalents of $V^{\prime} \mathrm{O}_{2}$ and $V^{\prime} \mathrm{CO}_{2}$ could also be explained by increased efficiency of 
peripheral muscle oxygen extraction after training, with less contribution from anaerobic metabolism during exercise [18]. A comparable observation was found after a moderate intensity exercise training in patients with moderate COPD [19]. However, as in the latter study, the possibility that the decreased ventilatory equivalents of $V^{\prime} \mathrm{O}_{2}$ and $V^{\prime} \mathrm{CO}_{2}$ are related to improved lung mechanics (i.e. a lower dead space ventilation) after training cannot be excluded.

In the interval training group, leg pain at $W_{\max }$ was dramatically decreased, despite an increase in lactate concentration and Wmax, suggesting an enhanced exercise tolerance. In contrast to the continuously trained group peak work rate was significantly increased in the interval trained group and maximal inspiratory mouth pressure also tended to show a more pronounced increase. The more pronounced improvement in exercise load, inspiratory muscle strength and change in the subjective score of leg pain in the interval trained group could be related to an increased muscle strength, being stressed during the short periods of training at $90 \%$ of peak work rate.

To the best of the authors' knowledge, this is one of the few randomized controlled studies investigating the effect of training modality in patients with severe chronic obstructive pulmonary disease. More insight into the (altered) exercise physiology in chronic obstructive pulmonary disease is necessary to be able to ascertain whether the commonly used training principles for healthy subjects are applicable in patients with severe chronic obstructive pulmonary disease. In addition to the studied metabolic and ventilatory responses in the current patients with severe chronic obstructive pulmonary disease, exercise training also resulted in decreased leg pain and in an increase in maximal inspiratory pressure. It is an attractive hypothesis to assume that these effects are related to changes on a muscular level but this remains to be determined via the investigation of muscle metabolism. Further research is therefore required to explore the effects of training modality on muscle metabolism in chronic obstructive pulmonary disease patients.

\section{References}

1. Donner CF, Muir JF. Selection criteria and programmes for pulmonary rehabilitation in COPD patients. Eur Respir J 1997; 10: 744-757.

2. McArdle WD, Katch FI, Katch VL. Exercise Physiology. 3rd Edn. Malvern, PA, Lea \& Febiger, 1991.

3. Casaburi R, Patessio A, Ioli F, Zanaboni S, Donner CF, Wasserman K. Reductions in exercise lactic acidosis and ventilation as a result of exercise training in patients with obstructive lung disease. Am Rev Respir Dis 1991; 143: 9-18.
4. Schols AMWJ, Mostert R, Soeters PB, Wouters EFM. Body composition and exercise performance in patients with chronic obstructive pulmonary disease. Thorax 1991; 46: 695-699.

5. Hamilton AL, Killian KJ, Summers E, Jones NL. Muscle strength, symptom intensity, and exercise capacity in patients with cardiorespiratory disorders. Am J Respir Crit Care Med 1995; 152: 2021-2031.

6. Maltais F, Simard A, Simard C, Jobin J, Desagnes P, Leblanc P. Oxidative capacity of the skeletal muscle and lactic acid kinetics during exercise in normal subjects and in patients with COPD. Am J Respir Crit Care Med 1996; 153: 288-293.

7. Smodlaka VN, Adamovich DR. Reconditioning of emphysema patients. NY State J Med 1974; 74: 951-955.

8. Black LF, Hyatt RE. Maximal respiratory pressures: normal values and relationship to age and sex. Am Rev Respir Dis 1969; 99: 696-702.

9. Schols AMWJ, Wouters EFM, Soeters PB, Westerterp KR. Body composition by bioelectrical impedance analysis compared to deuterium dilution and skinfold anthropometry in patients with chronic obstructive pulmonary disease. Am J Clin Nutr 1991; 52: 421-424.

10. Wasserman K, Hansen JE, Sue DY, Whipp BJ, Casaburi R. Principles of Exercise Testing and Interpretation. 2nd Edn. Philadelphia, Baltimore, Hong Kong, London, Munich, Sydney, Tokyo, Lea \& Febiger; 1994.

11. Pocock SJ. Clinical Trials: a Practical Approach. Chichester, New York, Brisbane, Toronto, Singapore, John Wiley \& Sons; 1991.

12. Anonymous. Pulmonary rehabilitation. Joint ACCP/ AACVRR Evidence-based guidelines. Chest 1997; 112: 1363-1396.

13. Maltais F, Leblanc P, Simard C, et al. Skeletal muscle adaptation to endurance training in patients with chronic obstructive pulmonary disease. Am J Respir Crit Care Med 1996; 154: 442-447.

14. Jakobsson P, Jorfeldt L, Henriksson J. Metabolic enzyme activity in the quadriceps femoris muscle in patients with severe chronic obstructive pulmonary disease. Am $J$ Respir Crit Care Med 1995; 151: 374-377.

15. Gorostiaga EM, Walter CB, Foster C, Hickson RC. Uniqueness of interval and continuous training at the same maintained exercise intensity. Eur J Appl Physiol 1991; 63: 101-107.

16. Bhambani $\mathrm{Y}$, Singh $\mathrm{M}$. The effects of three training intensities on $V^{\prime} \mathrm{O}_{2}$, max and $V^{\prime} \mathrm{E} / V^{\prime} \mathrm{O}_{2}$ ratio. Can J Appl Sport Sci 1985; 10: 44-51.

17. Poole DC, Gaesser GA. Response of ventilatory and lactate thresholds to continuous and interval training. $J$ Appl Physiol 1985; 58: 1115-1121.

18. Taylor $\mathrm{R}$, Jones $\mathrm{N}$. The reduction by training of $\mathrm{CO}_{2}$ output during exercise. Eur J Cardiol 1979; 9: 53-62.

19. Clark CJ, Cochrane L, Mackay E. Low intensity peripheral muscle conditioning improves exercise tolerance and breathlessness in COPD. Eur Respir J 1996; 9: 2590 2596. 